\title{
Optic disc morphology in premature infants
}

\author{
Sabine Hackl, ${ }^{1}$ Florian Zeman, ${ }^{2}$ Horst Helbig, ${ }^{1}$ Isabel Maria Oberacher-Velten ${ }^{1}$
}

${ }^{1}$ Department of

Ophthalmology, University Medical Centre Regensburg, Regensburg, Germany ${ }^{2}$ Centre for Clinical Studies, University Medical Centre Regensburg, Regensburg, Germany

\section{Correspondence to} I M Oberacher-Velten, Department of Ophthalmology, University Medical Centre Regensburg, Franz-JosefStrauß-Allee 11, 93053 Regensburg, Germany; isabel. velten@klinik.uni-regensburg. de

Received 18 May 2012 Revised 22 November 2012 Accepted 19 December 2012

\begin{tabular}{l} 
To cite: Hackl S, Zeman F, \\
Helbig H, et al. Br J \\
Ophthalmol 2013;97: \\
314-317. \\
\hline
\end{tabular}

\begin{abstract}
Background To date, little is known about the morphology of optic discs in premature infants. However, optic disc morphology and optic nerve development are two factors that potentially influence visual function in infants. Thus we analysed the morphology of the optic disc and its correlation with gestational age and birth weight.

Methods In a retrospective trial, we assessed the widefield images (RetCam system) of 111 optic discs of 61 premature infants. We evaluated the form of the optic disc, defined by the ratio of the vertical to the horizontal diameter, the presence or absence of visible disc cupping, the cup to disc ratio and the presence or absence of a double ring (a concentric paler zone around the optic disc).
\end{abstract}

Results 110 of 111 optic discs had a vertical-oval form. We found a significant negative correlation between the form of the optic disc and birth weight $(p=0.003)$ and gestational age $(p=0.03) ; 75 \%$ of optic discs showed a double ring and $89 \%$ had visible disc cupping.

Conclusions In our study, premature birth was associated with the presence of a double ring. A low birth weight and low gestational age influence the form of the optic disc.

\section{INTRODUCTION}

Several pathologies can cause significant visual impairment in premature infants, such as retinopathy of prematurity ${ }^{1}$ and optic disc anomalies. ${ }^{2-8}$ The latter can occur together with periventricular and intraventricular haemorrhage that result in optic nerve atrophy. ${ }^{9-12}$ Normal visual development however requires a normally functioning optic nerve. As the literature includes only a few $^{3} 4{ }^{13-18}$ reports on optic disc morphology in premature infants, we designed a retrospective clinical trial to evaluate a possible correlation between birth weight, gestational age and optic disc morphology in premature infants.

\section{MATERIALS AND METHODS}

The study was a retrospective clinical survey. All patients were examined for retinopathy of prematurity according to the national screening guidelines for premature infants. ${ }^{19}$ The trial was conducted in accordance with the ethical standards of the Declaration of Helsinki.

\section{Subjects}

Sixty-one consecutive premature infants born between November 2007 and December 2008 at St Hedwig's Hospital, Regensburg, Germany, were included in the study. All infants were born at a gestational age $\leq 32$ weeks or between 32 and 36 weeks with oxygen administration for more than 3 days, or had a birth weight $\leq 1500$ g. All infants were examined according to the national screening guidelines for retinopathy of prematurity. ${ }^{19}$

For evaluation of the first examination, two infants had to be excluded from the trial because of missing images. Furthermore, we excluded two infants with congenital anomalies of the optic disc (eg, micropapilla) and other retinal congenital anomalies. One image of an infant's right eye was excluded because of poor quality of the image. Fourteen infants had already been discharged at the time of the second examination.

\section{Methods of examination and data collection}

At the first examination, the medical history of all infants was recorded, including gestational age at birth, birth weight and postmenstrual age. All infants underwent a dilated fundus examination at at least two different time points. The first examination took place 5-6 weeks after birth and the second examination at the due date of the prematurely born infants. All infants were examined in the neonatal care unit of St Hedwig's Hospital. Prior to the examination, the infants' pupils were dilated with eye drops containing $0.1 \%$ atropine and $2 \%$ phenylephrine. Prior to insertion of an eyelid retractor, the cornea was anesthetised with oxybuprocain- $\mathrm{HCl}(4 \mathrm{mg} / \mathrm{ml})$ eye drops.

Fundoscopy using indirect ophthalmoscopy was conducted in each infant 6 weeks after birth and at the due date.

Retinal status was documented by taking widefield fundus photographs with a RetCam Eye Imaging System (Clarity Medical Systems Pleasanton, California, USA). Overall, we took nine pictures of each eye and used the most central picture for analysis.

All images were analysed with the software package Adobe Photoshop CS3, extended by two independent investigators ( $\mathrm{SH}, \mathrm{IMO}-\mathrm{V})$. The mean of these two measurements was used for further analysis. For each image, the optic disc was planimetrically gauged by marking the most superior, most inferior, most nasal and most temporal edge of the optic disc within the scleral Elschnig ring. In slightly tilted discs, an adjustment was made to take the top of the disc as the most superior edge. Distances between the points were measured in pixels. The vertical diameter (VD) of the optic disc was measured using the distance between the most superior and most inferior point; the horizontal diameter (HD) was measured using the most temporal and most nasal point. The form of the optic disc was defined by the ratio of VD to HD (VD/ HD). Instead of absolute measured data, we chose relative proportions and evaluated the presence or absence of an excavation of the optic disc. The 
horizontal extension of the excavation was measured using the most nasal and most temporal edge of the excavation, the vertical extension of the excavation by using the most superior and most inferior edge of the excavation. The size of the excavation was defined by the cup to disc ratio (CDR). CDR was defined by the ratio of horizontal excavation to HD. Additionally, the presence or absence of a double ring configuration of the optic disc was evaluated. The double ring was defined as a concentric paler zone surrounding the optic disc.

\section{Statistics}

Continuous variables are presented as means (SDs) and ranges (minimum to maximum); categorical variables are presented as absolute numbers and proportions.

We used linear mixed models to analyse the impact of each variable-gestational age and birth weight, time (first examination and examination at the actual calculated birth day) and eye (right and left)—on the form of the optic disc (VD/HD). The correlation structure between the two eyes was specified as unstructured, and the correlation structure over time was specified as autoregressive. As an additional factor, the interaction between gestational age and birth weight $\times$ time was included in the model. The dependency of $\mathrm{VD} / \mathrm{HD}$ (the mean values of both eyes) on gestational age or birth weight and the time of examination were illustrated as a scatterplot, accompanied by a regression line and corresponding 95\% confidence bands.

A logistic regression was conducted to analyse the risk of the presence of a double ring according to gestational age and birth weight.

All reported $p$ values are two sided, and a p value of 0.05 is considered the threshold of statistical significance. Because of the exploratory nature of our trial, no adjustment for multiple testing was done. Data entry and calculations were made with the software package SPSS 19.0 (Chicago, EUA), and the linear mixed model analyses were done with SAS 9.2 by the procedure PROC MIXED.

\section{RESULTS}

Mean gestational age of the 61 premature infants was 28.3 (SD 2.7) weeks (22-36 weeks of gestational age) and mean birth weight was $1135 \mathrm{~g}$ (SD $448 \mathrm{~g}$, range 320-2960 g). For the first examination, 111 optic discs of 56 premature infants were assessed and 94 optic discs of 47 infants for the second examination. The VD/HD and CDR values at the first examination and at the due date examination are summarised in table 1 . With $\mathrm{VD} / \mathrm{HD}$ as the dependent variable, the mixed model with gestational age at birth and time (first examination and examination at the due date) as independent variables resulted in a significant effect for gestational age $(p=0.030)$, time $(p=0.036)$ and

Table 1 Ratio of vertical and horizontal diameter, and cup to disc ratio at the first examination and at the due date

\begin{tabular}{|c|c|c|c|c|}
\hline & \multicolumn{2}{|l|}{ VD/HD ratio } & \multicolumn{2}{|l|}{ CDR } \\
\hline & $\begin{array}{l}\text { First } \\
\text { examination } \\
\text { (left } n=56 \\
\text { right } n=55 \text { ) }\end{array}$ & $\begin{array}{l}\text { Due date } \\
\text { (left and } \\
\text { right } n=47 \text { ) }\end{array}$ & $\begin{array}{l}\text { First } \\
\text { examination } \\
\text { (left } n=36 \\
\text { right } n=44 \text { ) }\end{array}$ & $\begin{array}{l}\text { Due date } \\
\text { (left } n=33 \text {, } \\
\text { right } n=35 \text { ) }\end{array}$ \\
\hline Left eye & $1.28(0.14)$ & $1.25(0.10)$ & $0.27(0.08)$ & $0.28(0.08)$ \\
\hline Right eye & $1.28(0.13)$ & $1.26(0.14)$ & $0.30(0.11)$ & $0.31(0.09)$ \\
\hline
\end{tabular}

interaction between gestational age and time $(p=0.047)$. This interaction effect was caused by changes in the VD/HD ratio that occurred in the period between the two examinations, and this change was higher the earlier the premature infant was born.

With birth weight and time as independent variables, only birth weight resulted in a significant effect $(p=0.003)$, whereas time $(p=0.075)$ and time $\times$ birth weight $(p=0.206)$ showed no effect. Neither model showed any significant difference between the left and right eyes $(p=0.82$ and $p=0.86)$. A graphical illustration of both models is given in figure 1 .

At the first examination, a double ring configuration was present in 84 eyes from 42 infants; 14 infants had no double ring and five infants could not be evaluated for technical reasons. In all infants, the double ring was either present
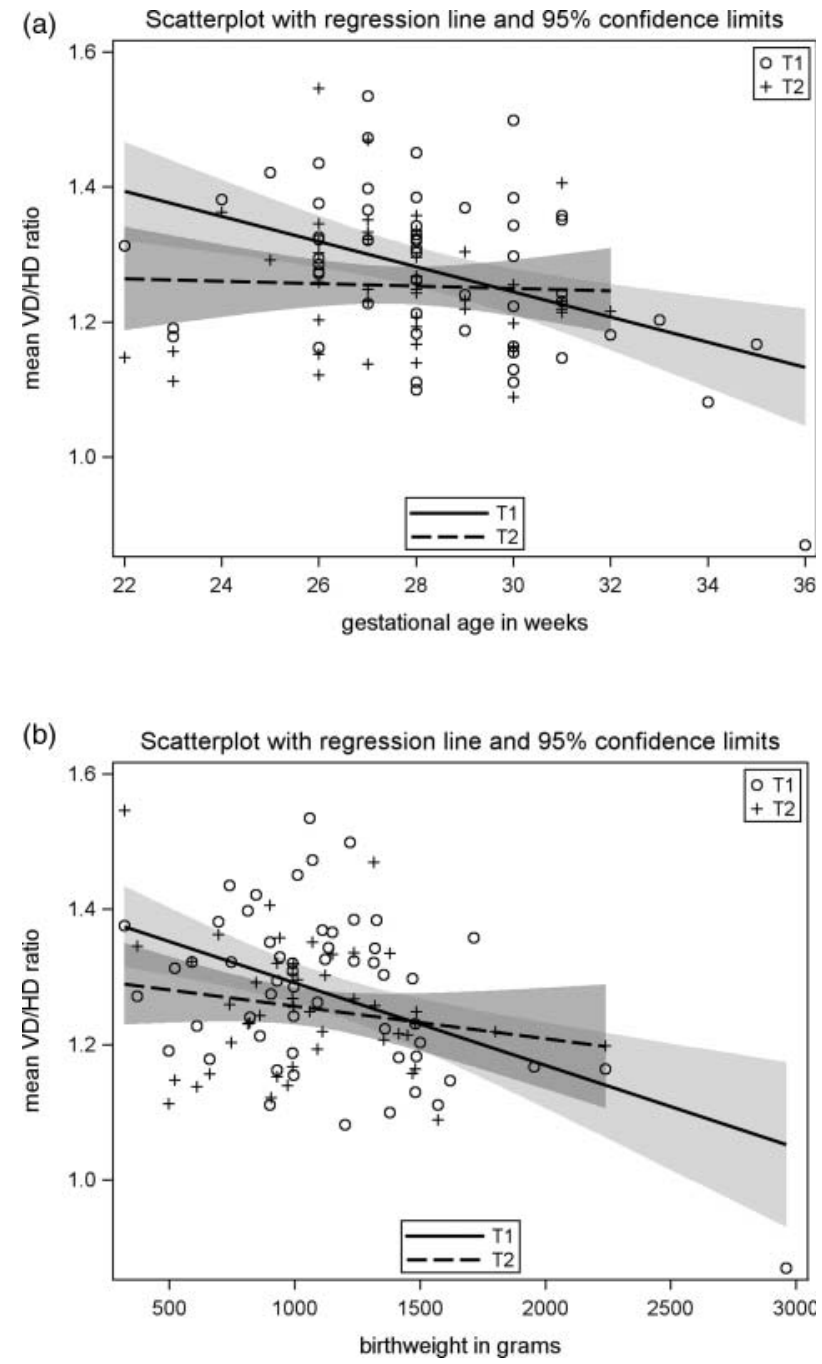

Figure 1 (A) Correlation between gestational age at birth and mean vertical diameter (VD)/horizontal diameter (HD) ratio. In all premature infants, the first examination was performed 5-6 weeks after birth (T1) and at the due date (T2, 40 weeks' postmenstrual age). Thus $T 1$ was an individual time point for each infant and took place at a lower postmenstrual age in infants with a lower gestational age at birth. Postmenstrual age was equal for all infants at T2 (40 weeks).

(B) Correlation between birth weight and mean VD/HD ratio. In all premature infants, the first examination was performed 5-6 weeks after birth (T1) and at the due date (T2, 40 weeks' postmenstrual age) (compare with $(A)$ ). 
bilaterally or missing bilaterally. Logistic regression could not show any significant effect of gestational age $(\mathrm{OR}=1.02$; $p=0.866)$ or birth weight $(\mathrm{OR}=1.00 ; \mathrm{p}=0.785)$ for an increased risk of the occurrence of a double ring.

A visible excavation of the optic disc was present in 44 right eyes and 36 left eyes at the first examination (in 30 infants the excavation was present in both eyes) and in 35 right eyes and in 33 left eyes at the second examination (in 27 infants the excavation was present in both eyes). Measurement of the optic cup was difficult. Because of the possibility of measurement error, especially when the excavation was very small, we abandoned further statistical analyses to avoid biased results. Qualitatively, the ISNT rule of adult optic discs seemed to apply to the discs of premature infants.

\section{DISCUSSION}

In the present study, we found that the optic discs of almost all (except one) eyes examined showed a vertical-oval form with a mean VD/HD ratio of 1.28 . The data also showed that a low birth weight and low gestational age influenced the form of the optic disc. The lower the birth weight, the more vertical-oval was the optic disc (figure 1B). Gestational age had the same influence on the optic disc (figure 1A). Interestingly, the influence of birth weight and gestational age regressed between the first and second examinations, suggesting that the form of the optic disc significantly changes after birth in premature infants and tends to normalise during the first weeks after birth. There was a greater difference between VD/HD measured at the first examination and at the due date the earlier the premature infant was born. However, as infants born with a lower gestational age had their first examination at a lower postmenstrual age (5-6 weeks after birth), a conclusion regarding the velocity of optic disc change between premature infants with different gestational ages at birth is not possible from the data of our study.

Eighty-four of $112(75 \%)$ eyes examined showed a double ring sign and $73 \%$ showed visible disc cupping.

Other studies have analysed optic disc morphology of preterm infants in formalin fixed eyes, ${ }^{13}$ in infants while preterm $^{14}{ }^{17}$ and in older children who were born preterm. $^{3} 4619$ Furthermore, different methods were used for analyses. While de Silva et $a l^{14}$ and McLoon et al ${ }^{17}$ used digital images, Hellström ${ }^{3}{ }^{4}$ and Jacobson ${ }^{14}$ used digitised fundus photographs.

Rimmer et $a l^{13}$ examined 20 formalin fixed eyes of infants born before 40 weeks of gestation post mortem. A mean HD of 0.93 and a mean VD of 1.10 was reported, resulting in a VD/ HD ratio of 1.18 , although the use of formalin might have altered these findings. In contrast with these findings and the results of the present study, published measurements of adult optic disc dimensions ${ }^{20}$ assume a VD/HD ratio for adults of 1.09 and thus an almost round shape of the optic disc.

Rimmer et $a l^{13}$ measured the VD and HD of the optic disc and retrobulbar optic nerve in eyes from 95 patients (age range at death 4.8 months' gestation to 21.9 years) on whom autopsies were performed. The authors ${ }^{13}$ reported that approximately $50 \%$ of the growth of the optic disc and nerve occurred within the first 20 weeks of gestation; $75 \%$ of the growth is finished at birth, and $95 \%$ before the age of 1 year.

The following studies evaluated optic disc morphology of preterm born infants and children in vivo. Optic discs of infants while preterm were studied by de Silva ${ }^{14}$ and McLoone. ${ }^{17}$ In an in vivo imaging study including 51 premature infants, De Silva et $a l^{14}$ found a mean HD of $1.05 \mathrm{~mm}$ and a mean VD of $1.41 \mathrm{~mm}$ resulting in a VD/HD ratio of 1.34 . The VD/HD ratio found in our study is consistent with the findings of the two above mentioned studies. McLoone et $a l^{17}$ assessed optic disc diameter, optic disc area and optic disc cup in 109 premature infants with and without ischaemic brain injury. The evaluation revealed an increased incidence of optic nerve hypoplasia $(\mathrm{ONH})$ in premature infants with intraventricular haemorrhage grade 4 . They found no association between disc morphology and timing of brain injury. As in our study, de Silva ${ }^{14}$ and Mc Loone ${ }^{17}$ used digital fundus photographs for analysis of the optic disc.

Optic discs of older children who were born preterm were evaluated by Hellström, Wikstrand and Jacobson. A study by Hellström et $a l^{3}$ with significantly older children (mean age 4.8 years, comparing 39 ex-preterm children born before 32 weeks of gestation and 39 healthy full term children) did not show a significant difference in the optic disc. According to another study by Hellström et al, ${ }^{4}$ examining 50 ex-preterm children with a mean age of 7 years, optic disc cupping is a frequent finding in prematurely born infants; $80 \%$ of the formerly prematures examined by Hellström had a mean birth weight of $1055 \mathrm{~g}$ and disc cupping. This correlates with the findings in our study, in which $73 \%$ of the examined prematures had disc cupping. Wikstrand et al ${ }^{18}$ examined 53 children born at a gestational age $<32$ weeks at a mean age of 5.4 years. They found that low birth weight and poor weight gain during the first weeks of life were associated with a larger area of the optic cup as well as with a smaller neuronal rim area of the optic nerve head. Jacobson et $a l^{6}$ assessed optic disc area, cup area and rim area of 35 ex-preterm children with periventricular white matter damage and a mean age of 7 years. They found that children with periventricular leucomalacia or periventricular haemorrhage had a significantly larger cup area than the control group and a significantly smaller neuroretinal rim area than controls. Those children estimated to have a brain lesion before 28 weeks of gestation had a small optic disc area.

In contrast with the previously mentioned studies of de Silva, ${ }^{13}$ McLoone $^{17}$ and the present study, Hellström, ${ }^{3}{ }_{4}^{4}$ Wikstrand $^{18}$ and Jacobson ${ }^{6}$ took digitised fundus photographs to analyse the optic disc of the children.

$\mathrm{ONH}$ is a developmental anomaly of the optic nerve characterised by a diminished number of optic nerve fibres in the optic nerve $^{21}$ and a small optic disc. ${ }^{22}$ The double ring sign is said to be associated with $\mathrm{ONH}^{22}{ }^{23}$ In the present study, we found the double ring sign in a high proportion of eyes (75\%), which remained unchanged between the two examinations. Fledelius ${ }^{15}$ described a double ring sign in $23 \%$ of cases and suggested that the double ring sign is a normal stage of disc development. In our study, the proportion of eyes with the double ring sign was considerably higher and did not regress up to the due date. Thus we suggest that this sign is a frequent phenomenon in premature infants.

In the above mentioned study on ocular features in premature infants by Fledelius, ${ }^{15}$ optic discs showed an elliptic contour and also a double contour of the disc margins, but both phenomena regressed within 1-2 years. In our study, the form of the optic discs significantly changed between the first and second examinations insofar that the discs were rounder but still highly oval. Only one double ring had regressed but, in our study, the follow-up interval was defined up to the due date.

In conclusion, our study suggests that a significantly verticaloval form of the optic disc in premature infants correlates with a low birth weight and low gestational age. A double ring sign was frequently found in infant optic discs. The individual courses and time points of further optic disc development during the first years of life still need to be investigated further. 
Acknowledgements The authors thank Ms Monika Schoell for linguistic review of this manuscript.

Contributors SH contributed to the analysis and interpretation, writing the article, final approval of the article, data collection and literature search. FZ contributed to the analysis and interpretation, statistical analysis, writing the article and final approval of the article. $\mathrm{HH}$ contributed to the critical revision and final approval of the article. IMO-V contributed to the conception and design of the study, analysis and interpretation, writing the article, final approval of the article, data collection and literature search.

\section{Competing interests None.}

Ethics approval The study was a retrospective data evaluation. The data were collected during routine screening examinations. All data were analysed anonymously and thus ethics committee approval was not obtained.

Provenance and peer review Not commissioned; externally peer reviewed.

Data sharing statement The corresponding author confirms that she has full access to all of the data analysis. Unpublished anonymised photographs are available from $\mathrm{SH}, \mathrm{HH}$ and IMO-V.

\section{REFERENCES}

1 Roodhooft JM. Leading causes of blindness worldwide. Bull Soc Belge Ophtalmol 2002;19-25

2 Dowdeswell HJ, Slater AM, Broomhall J, et al. Visual deficits in children born at less than 32 weeks' gestation with and without major ocular pathology and cerebral damage. Br J Ophthalmol 1995;79:447-52.

3 Hellström A, Hård AL, Chen $Y$, et al. Ocular fundus morphology in preterm children. Influence of gestational age, birth size, perinatal morbidity, and postnatal growth. Invest Ophthalmol Vis Sci 1997:38:1184-92.

4 Hellström A, Hård AL, Svensson E, et al. Ocular fundus abnormalities in children born before 29 weeks of gestation: a population based study. Eye 2000;14:324-9.

5 Brodsky MC. Congenital optic disk anomalies. Surv Ophthalmol 1994;39:89-112.

6 Jacobson L, Hard AL, Svensson E, et al. Optic disc morphology may reveal timing of insult in children with periventricular leucomalacia and/or periventricular haemorrhage. Br J Ophthalmol 2003;87:1345-9.

7 Brodsky MC, Fray KJ, Glasier CM. Perinatal cortical and subcortical visual loss: mechanisms of injury and associated ophthalmologic signs. Ophthalmology 2002:109:85-94.
8 Brodsky M, Glasier C. Optic nerve hypoplasia: clinical significance of associated central nervous system abnormalities in magnetic resonance imaging. Arch Ophthalmol 1993;111:66-74.

9 O'Keefe M, Kafil-Hussain N, Flitcroft I, et al. Ocular significance of intraventricular haemorrhage in premature infants. Br J Ophthalmol 2001;85:357-9.

10 Christiansen SP, Fray KJ, Spencer T. Ocular outcomes in low birth weight premature infants with intraventricular hemorrhage. J Pediatr Ophthalmol Strabismus 2002:39:157-65.

11 Asproudis IC, Andronikou SK, Hotoura EA, et al. Retinopathy of prematurity and other ocular problems in premature infants weighing less than $1500 \mathrm{~g}$ at birth. Eur J Ophthalmol 2002;12:506-11.

12 Mudgil AV, Repka MX. Childhood optic atrophy. Clin Experiment Ophthalmol 2000;28:34-7.

13 Rimmer S, Keating C, Chou T, et al. Growth of the human optic disc and nerve during gestation, childhood and early adulthood. Am J Ophthalmol 1993; 116:748-53.

14 De Silva DJ, Cocker KD, Lau G, et al. Optic disc-to-fovea distance in preterm and full-term infants. Invest Opthalmol Vis Sci 2006:47:4683-6.

15 Fledelius HC. Ocular features other than retinopathy of prematurity in the pre-term infant. Acta Ophthalmol (Copenh) 1990;68:214-17.

16 Fledelius HC. Optic disc cupping and prematurity. Large cups as a possible low birthweight sequel. Acta Ophthalmol (Copenh) 1978;56:563-7317.

17 McLoone $\mathrm{E}$, O'Keefe M, Donoghue $\mathrm{V}$, et al. RetCam image analysis of optic disc morphology in premature infants and its relation to ischaemic brain injury. $\mathrm{Br} J$ Ophthalmol 2006;90:465-71.

18 Wikstrand MH, Hard A-L, Niklasson A, et al. Birth weight deviation and early postnatal growth are related to optic nerve morphology at school age in children born preterm. Pediatr Res 2010;67:325-9.

19 Jandeck C, Kellner U, Lorenz B, et al. Guidelines for ophthalmological screening of premature infants in Germany. Klin Monatsbl Augenheilkd 2008;225:123-30.

20 Jonas JB, Gusek GC, Naumann GO. Optic disc cup and neuroretinal rim size, configuration and correlations in normal eyes. Invest Ophthalmol Vis Sci 1988;29:1151-8.

21 Zeki SM, Dutton GN. Optic nerve hypoplasia in children. Br J Ophthalmol 1990;74:300-4.

22 Novak JM, McLaren P. Optic nerve hypoplasia. J Am Optom Assoc 1987;58:122-6.

23 Beuchat L, Safran AB. Optic nerve hypoplasia: papillary diameter and clinical correlation. J Clin Neuroophthalmol 1985;5:249-53. 


\section{Optic disc morphology in premature infants}

Sabine Hackl, Florian Zeman, Horst Helbig and Isabel Maria

Oberacher-Velten

Br J Ophthalmol 2013 97: 314-317

doi: 10.1136/bjophthalmol-2012-302066

Updated information and services can be found at:

http://bjo.bmj.com/content/97/3/314

\section{These include:}

References This article cites 22 articles, 8 of which you can access for free at: http://bjo.bmj.com/content/97/3/314\#BIBL

Email alerting Receive free email alerts when new articles cite this article. Sign up in the service box at the top right corner of the online article.

Topic Articles on similar topics can be found in the following collections Collections

Paediatrics (358)

\section{Notes}

To request permissions go to:

http://group.bmj.com/group/rights-licensing/permissions

To order reprints go to:

http://journals.bmj.com/cgi/reprintform

To subscribe to BMJ go to:

http://group.bmj.com/subscribe/ 